\title{
Pemberdayaan masyarakat dengan pelatihan pembuatan minuman kesehatan dari Tanaman Obat Keluarga (TOGA)
}

\author{
Erna Harfiani ${ }^{\star 1}$, Anisah $^{2}$, \& Agneta Irmarahayu ${ }^{2}$ \\ ${ }^{1}$ Departemen Farmakologi, Fakultas Kedokteran, UPN Veteran Jakarta \\ ${ }^{2}$ MEU Fakultas Kedokteran, UPN Veteran Jakarta \\ *erna.hf@gmail.com
}

\begin{abstract}
Health is important to maintain and prevents disease by maintaining health better than treating disease. Depok (West Java), is a fertile area but is quite densely populated, land for planting crops, including TOGA is limited. To motivate people to plant TOGA, training is needed to make health drinks to maintain daily health. Training in making health drinks can further motivate people to plant TOGA in the home yard. This training was preceded by counseling about TOGA and its benefits, especially turmeric (Curcuma domestica) and red ginger (Zingiber officinale L.). This training aims to make people understand more about the importance of planting TOGA, its use in maintaining daily health and being able to make health drinks that can prevent disease more than treat diseases, by consuming health drinks made independently. The results were the increasing knowledge of the community in RW 03 Depok Jaya Depok, about the importance of planting TOGA in the home yard and being able to make health drinks in the form of tamarind turmeric and red ginger powder.
\end{abstract}

Absrak Kesehatan penting untuk dijaga dan pencegahan penyakit dengan menjaga kesehatan lebih baik daripada mengobati penyakit. Masyarakat Depok, Jawa Barat termasuk daerah yang subur namun cukup padat penduduknya sehingga lahan untuk menanam tanaman, termasuk TOGA terbatas. Untuk memotivasi masyarakat menanam TOGA, diperlukan pelatihan membuat minuman kesehatan yang dapat dilakukan secara mandiri untuk menjaga kesehatan sehari hari secara sederhana. Pelatihan pembuatan minuman kesehatan dapat lebih memotivasi masyarakat untuk menanam TOGA di pekarangan sekitar rumah. Pelatihan ini sebelumnya didahului dengan penyuluhan tentang TOGA dan manfaatnya terutama kunyit (Curcuma domestica) dan jahe merah (Zingiber officinale $L$ ). Pelatihan ini bertujuan agar masyarakat dapat lebih paham tentang pentingnya menanam TOGA, pemanfaatannya dalam menjaga kesehatan sehari hari dan dapat membuat minuman kesehatan. Dengan pelatihan ini juga diharapkan masyarakat dapat lebih mencegah penyakit daripada mengobati penyakit, dengan mengkonsumsi minuman kesehatan yang dibuat secara mandiri. Hasil yang dicapai dari kegiatan ini adalah meningkatnya pengetahuan masyarakat di RW 03 Depok Jaya Pancoran Mas Depok tentang pentingnya menanam TOGA di pekarangan rumah, dan mampu membuat minuman kesehatan berupa kunyit asam dan serbuk jahe merah.

Keywords: TOGA; health drink; Depok; home yard

\section{ठ OPEN ACCESS}

Citation: Harfiani, E., Anisah, \& A. Irmarahayu. 2019. Pemberdayaan masyarakat dengan pelatihan pembuatan minuman kesehatan dari Tanaman Obat Keluarga (TOGA). Riau Journal of Empowerment 2(2): 37-42 https://doi.org/10.31258/raje.2.2.37-42

Paper type: Community service

Received: 2019-02-11, Revised: 2019-08-23, Accepted: 2019-08-30

Language: Bahasa Indonesia (id)

Funding: Kegiatan pengabdian masyarakat didanai oleh LPPM UPN "Veteran" Jakarta.

ISSN 2623-1549 (online), 2654-4520 (print)

(C) 2019 Erna Harfiani et al. The article by Author(s) is licensed under a Creative Commons Attribution 4.0 International License. This license permits unrestricted use, distribution, and reproduction in any medium, provided the original author and source are credited. 


\section{PENDAHULUAN}

Indonesia termasuk daerah yang beriklim subtropis sehingga tanaman dapat tumbuh sangat melimpah, bahkan menjadi negara kedua setelah Brazil dengan kekayaan keanekaragaman hayati (Acuan Sediaan Herbal, 2006). Kondisi ini memungkinkan masyarakat Indonesia dapat menanam bermacam-macam tanaman di pekarangan rumah. Kota Depok dengan luas wilayah $200,29 \mathrm{~km}^{2}$, mempunyai temperatur $24,3-33^{\circ} \mathrm{C}$, penyinaran matahari rata-rata $49,8 \%$, kelembaban udara $25 \%$ dan jumlah curah hujan 222 hari/tahun merupakan iklim yang cukup baik bagi tumbuh suburnya berbagai tanaman (Profil Kesehatan Kota Depok, 2013). Disetiap rumah masyarakat Indonesia biasanya terdapat tanaman yang berfungsi sebagai tanaman hias, penghijauan atau fungsi lainnya. Rumah yang sehat dan asri akan memiliki pekarangan yang memberikan kontribusi untuk penghijauan dan keindahan. Sealin itu tanaman pekarangan dapat bernilai ekonomi (Soverda et al., 2018; Duaja et al., 2018). Lahan pekarangan rumah dapat ditanam berbagai Tanaman Obat Keluarga (TOGA), yang dapat dimanfaatkan untuk menjaga kesehatan masyarakat sehari hari (Winarto, 2007; Suparni \& Wulandari, 2012). Diharapkan masyarakat secara luas dapat memanfaatkan TOGA dari lahan pekarangan rumah sehingga membantu meningkatkan kesehatan masyarakat (Hastuti et al., 2014). Namun sayangnya saat ini penanaman dan pemanfaatan tanaman obat keluarga (TOGA) belum dilakukan secara maksimal (Tuloli et al., 2016). Masyarakat RW 03 Depok Jaya Pancoran Mas Depok belum memanfaatkan pekarangan rumah untuk menanam TOGA secara maksimal, pekarangan rumah masih sebatas untuk penghijauan dan menambah keindahan rumah.

Diperlukan pemahaman dari masyarakat untuk dapat memanfaatkan pekarangan sekitar rumah selain hanya untuk penghijauan dan menambah keindahan rumah, dapat untuk menanam TOGA di pekarangan rumah. Tiap tanaman TOGA mempunyai manfaat yang berbeda tergantung khasiat yang terkandung didalamnya (Supriatna et al., 2012; Kementerian Kesehatan RI, 2011a; Serial Teknologi Obat Asli, 2014). Hal ini dapat dimanfaatkan oleh masyarakat untuk menjaga kesehatan secara sederhana dalam kehidupan sehari hari, misalnya mengobati demam, mimisan, mengurangi keluhan di pencernaan dan lain lain (Herbal Indonesia Berkhasiat, 2008; Suharmiati \& Handayani, 2007; Mun'im, 2011). Oleh karena itu perlu diadakan banyak penyuluhan tentang TOGA dan pemanfaatannya yang tentunya dapat membuka wawasan masyarakat tentang pentingnya menjaga kesehatan sehari hari. Penyuluhan tentang TOGA dilakukan di masyarakat RW 03 Depok Jaya Pancoran Mas Depok.

\section{METODE PENERAPAN}

Sebelum dilakukan pelaksanaan kegiatan pengabdian masyarakat ini, dilakukan beberapa persiapan, yaitu:

1. Melakukan koordinasi kepada Ketua RW dan ketua PKK RW 03 Depok Jaya Pancoran Mas Depok Jawa Barat beserta jajarannya. Diperlukan dukungan dari pihak mitra abdimas, terutama pimpinan dan tokoh masyarakat demi lancarnya kegiatan abdimas. Dilakukan koordinasi sebanyak 2 kali bersama mitra masyarakat untuk mematangkan pelaksanaan kegiatan.

2. Pembuatan materi penyuluhan tentang TOGA yang berisi tentang khasiat beberapa TOGA terutama yang dapat ditaman di pekarangan rumah, khususnya tanaman Kunyit dan Jahe.

3. Pembuatan materi pendukung lainnya yaitu berupa pamflet dan buku saku yang dapat menambah pengetahuan masyarakat, sehingga lebih memotivasi untuk menanam TOGA dan memanfaatkannya berupa pembuatan minuman kesehatan.

4. Membuat kuesioner berupa posttest dan pretest yang akan diberikan kepada masyarakat untuk menilai tingkat pemahaman peserta (Syahza et al., 2018) sebelum dan sesudah penyuluhan dan pelatihan serta untuk melihat keefektifan kegiatan ini. 
5. Mempersiapkan TOGA berupa rimpang, yaitu tanaman kunyit dan jahe merah yang akan dibagikan kepada seluruh peserta penyuluhan dan pelatihan abdimas, sehingga memudahkan masyarakat untuk langsung menanam TOGA di pekarangan rumahnya.

Pelaksanaan kegiatan ini dilakukan dengan 2 tahapan, yaitu penyuluhan dan pelatihan pembuatan minuman kesehatan.

Harfiani et

al.

\section{Tahap Penyuluhan}

Pemahaman tentang TOGA pada masyarakat dapat ditingkatkan dengan cara memberikan penyuluhan kepada masyarakat sehingga masyarakat dapat termotivasi untuk memanfaatkan pekarangan rumah untuk menanam TOGA. Ibu-ibu yang tersebar di beberapa RT dalam lingkup PKK RW 03 Depok Jaya Pancoran Mas Depok Jawa Barat menjadi peserta penyuluhan. Kegiatan ini bertujuan untuk memberikan informasi tentang pentingnya menanam TOGA, khususnya jenis rimpang seperti tanaman jahe merah dan kunyit yang mempunyai banyak manfaat untuk menjaga kesehatan dan dapat mengurangi keluhan berbagai penyakit dalam kehidupan sehari hari. Teknis pelaksanaannya, ibu-ibu di wilayah RW 03 Depok Jaya Depok pada awalnya diberikan pretest yang berisi beberapa pertanyaan tentang pengetahuan TOGA secara umum. Dilakukan Pretest untuk menguji sejauh mana tingkat pengetahuan peserta terhadap materi yang akan disampaikan. Dilanjutkan dengan penyuluhan tentang TOGA dan ditutup dengan pengisian posttest kembali. Dengan pemberian Posttest kepada peserta, akan dapat memberi gambaran kepada pengabdi sejauh mana pemahaman peserta tentang materi yang telah disampaikan, dan diharapkan adanya peningkatan pengetahuan peserta. Untuk lebih memotivasi peserta untuk menanam dan memanfatkan TOGA, peserta juga diberikan leaflet dan buku saku tentang TOGA yang mengandung informasi penting dan bermanfaat berkenaan dengan TOGA sebagai bekal untuk diri sendiri maupun sumber informasi yang dapat disebarluaskan kembali ke masyarakat sekitar.

\section{Tahap Pelatihan dan Praktek langsung}

Setelah diberikan tambahan pengetahuan dari penyuluhan, maka selanjutnya dilakukan pelatihan pembuatan minuman kesehatan. Pelatihan ini bertujuan untuk mengajarkan kepada masyarakat cara membuat minuman kesehatan dari bahan tanaman TOGA berupa rimpang khususnya tanaman jahe merah dan kunyit. Ada dua bentuk minuman kesehatan yang dibuat yaitu minuman segar kunyit asam (berbahan dasar kunyit/Curcuma domestica dan serbuk minuman jahe merah (berbahan dasar jahe merah/Zingiber officinale L. (Sutrisno, 1998). Peserta dibagi menjadi beberapa kelompok kecil dan peserta diajarkan cara membuat minuman keehatan ini step by step, sehingga diharapkan peserta mampu untuk membuatnya secara mandiri. Peserta mendapat paket bahan TOGA untuk membuat minuman kesehatan untuk selanjutnya peserta membuat minuman kesehatannya secara berkelompok.

Dan di akhir kegiatan pelatihan semua peserta mendapatkan bibit tanaman jahe merah dan kunyit untuk ditaman di pekarangan rumah yang kelak hasilnya dapat digunakan membuat minuman kesehatan secara mandiri.

\section{HASIL DAN KETERCAPAIAN SASARAN}

\section{Penyuluhan}

Peserta penyuluhan yang terdiri dari masyarakat di daerah RW 03 Depok Jaya kelurahan Pancoran Mas Depok Jawa Barat, yang tergabung dalam ibu-ibu PKK RW 03 berkumpul di aula RW 03 Depok Jaya. Dilakukan penyuluhan tentang TOGA yang berisi pengertian, pemanfaatan dan pembagian serta macam-macam contoh TOGA, terutama yang berasal dari rimpang yang dapat dimanfaatkan sebagai minuman kesehatan. Kegiatan dimulai dengan pemberian pretest yang berisi beberapa pertanyaan tentang TOGA, hal ini perlu dilakukan untuk dapat menilai sejauh mana pemahaman dasar peserta sebelum mendapatkan penyuluhan. Selanjutnya dilakukan pemaparan materi TOGA selama 1 jam pemaparan. 
Sepanjang pemaparan, peserta aktif berinteraksi dengan pengabdi dengan antusias memberikan pertanyaan seputar isi materi. Umumnya peserta yang hadir telah memiliki pengetahuan tentang TOGA walau terbatas, dan dengan adanya penyuluhan pengetahuan kepada masyarakat terhadap TOGA ini pengetahuan masyarakat menjadi semakin meningkat. Peningkatan pengetahuan ini dapat diketahui dengan hasil penilaian posttest yang dilakukan setelah selesai pemaparan penyuluhan. Hasil nilai rata-rata pretest peserta yaitu dari nilai 64,0 ternyata mengalami peningkatan pada posttest menjadi bernilai 73,2 . Suasana penyuluhan dapat terlihat pada Gambar 1.
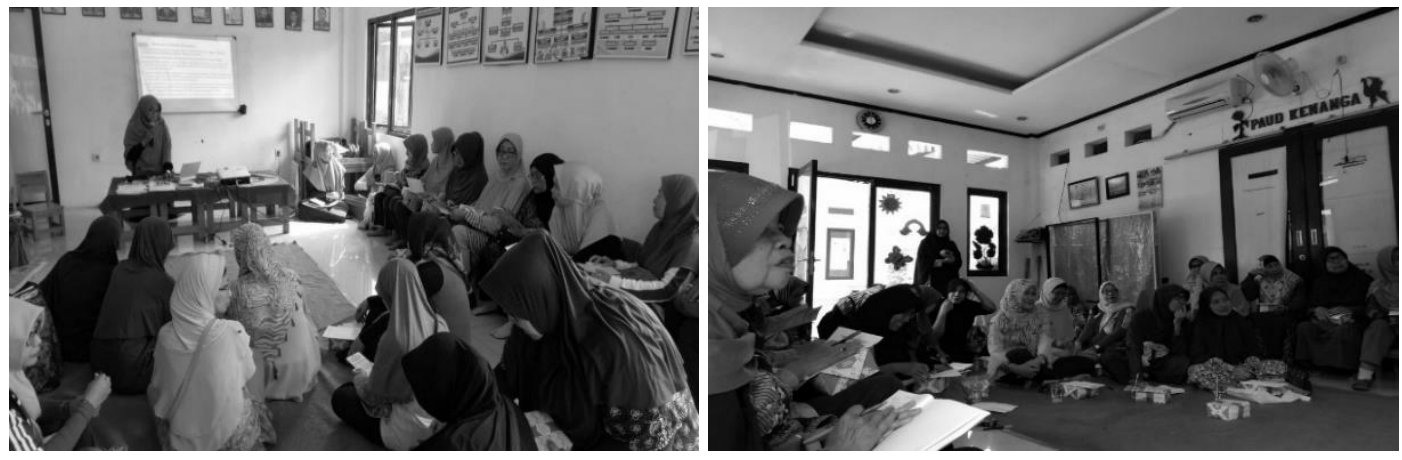

Gambar 1. Peserta penyuluhan ibu-ibu PKK RW 03 Depok Jaya Jawa Barat

\section{Pelatihan Membuat Minuman kesehatan}

TOGA sangat bermanfaat bagi masyarakat untuk menjaga kesehatan sehari hari secara sederhana. Dengan adanya pelatihan membuat minuman kesehatan masyarakat akan lebih termotivasi untuk menanam TOGA di pekarangan rumah dan hasilnya dapat dimanfaatkan. Pelatihan dilakukan setelah penyuluhan dan sesi tanya jawab selesai. Bahan-bahan yang diperlukan dalam pelatihan membuat minuman kesehatan sudah disiapkan oleh team pengabdian masyarakat, sedangkan untuk kompor gas yang diperlukan untuk memasak, dibantu disiapkan oleh peserta.

Peserta terlebih dahulu diberikan penjelasan step by step tentang cara pembuatan minuman kesehatan, peserta terlihat antusias untuk terlibat langsung dalam proses pembuatan, langkah demi langkah, mulai dari persiapan semua bahan yang digunakan termasuk ukuran jumlah masing-masing bahan dan membersihkan bahan sampai proses pematangan minuman kesehatan (Kementerian Kesehatan RI, 2011b; Kementerian Kesehatan RI, 2012). Bahanbahan yang diperlukan untuk pembuatan kunyit asam adalah biang dan rimpang kunyit, asam jawa, kayu manis, jahe, gula aren dan air (Dalimartha, 2000). Sedangkan bahan bahan yang diperlukan untuk membuat serbuk jahe merah adalah biang dan rimpang jahe merah, kapulaga, cengkeh, kayu manis, gula pasir dan air. Diperlukan cara khusus sehingga minuman dapat dibuat menjadi bentuk serbuk, yaitu dengan diberi tambahan gula pasir dan disangrai agak lama sampai mengental dan akhirnya menjadi serbuk. Saat pengolahan membuat serbuk jahe merah diperlukan tenaga yang cukup kuat untuk menyanggrai campuran bahan jahe merah menjadi bentuk serbuk karena prosesnya yang cukup lama, yaitu sekitar satu sampai dua jam. Hasil dari minuman berbentuk serbuk ini mempunyai kelebihan daripada bentuk minuman segar langsung, karena dapat disimpan lebih lama dan dapat dinikmati sewaktu-waktu. Dari kegiatan pembuatan minuman kunyit asam dan serbuk jahe merah, minuman yang telah selesai dibuat kemudian dibagikan kepada seluruh peserta agar mereka dapat merasakan minuman tersebut sehingga diharapkan dapat lebih termotivasi untuk dapat membuat sendiri di rumah, dan pada selanjutnya diharapkan masysarakat juga termotivasi untuk membudidayakan TOGA dipekarangan rumahnya. Hasil dari kegiatan pengabdian masyarakat berupa pelatihan ini adalah masyarakat mampu membuat minuman kesehatan secara mandiri baik berupa minuman segar kunyit asam maupun jahe merah dalam bentuk serbuk. Kedepannya masyarakat dapat menggunakan pengetahuan dan ketrampilan ini dengan memproduksi minuman kesehatan untuk dapat dijual dan bernilai ekonomis sehingga dapat meningkatkan perekonomian 
masyarakat. Gambar 2 memperlihatkan peserta yang sedang aktif membuat minuman kesehatan berbahan TOGA.

Harfiani et

al.

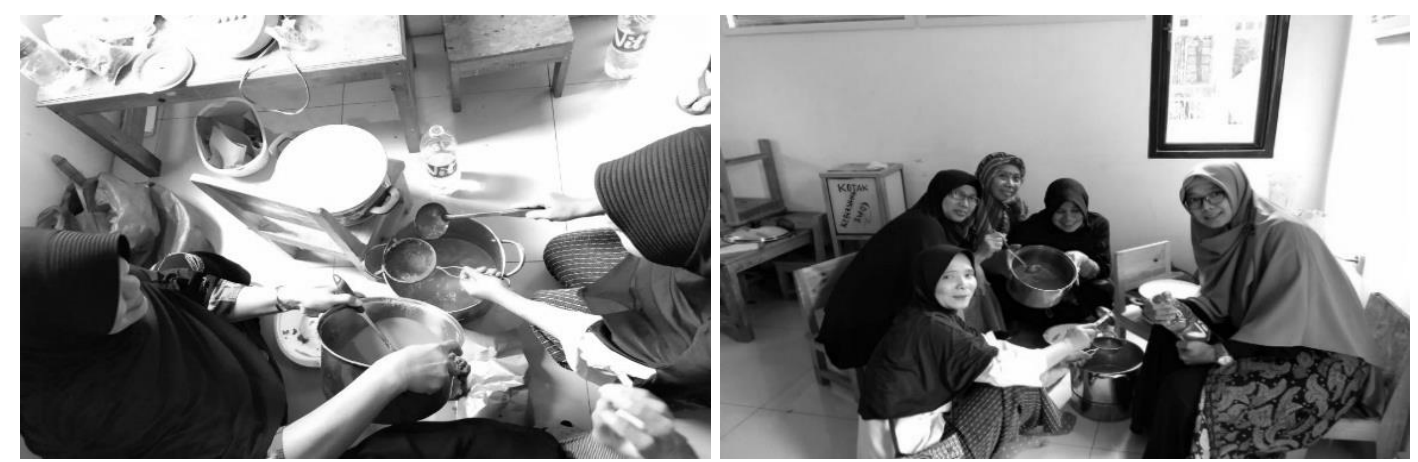

Gambar 2. Ibu-ibu PKK RW 03 Depok Jaya Jawa Barat praktek membuat minuman

\section{KESIMPULAN}

Kegiatan pelatihan pembuatan minuman kesehatan ini yang didahului dengan penyuluhan untuk meningkatkan pemahaman masyarakat RW 03 Depok Jaya Pancoran Mas Depok Jawa Barat, tentang TOGA ini dapat berjalan dengan baik dan lancar serta bermanfaat bagi peserta, hal ini dibuktikan dengan adanya peningkatan pengetahuan peserta dari hasil pretest dibandingkan dengan nilai posttest.

Pelatihan pembuatan minuman kesehatan ini diikuti oleh peserta dengan antusias, peserta dapat mengikuti semua tahapan pembuatan minuman kesehatan step by step dari awal penyiapan bahan sampai didapat hasil akhir minuman kesehatan, baik berupa minuman segar kunyit asam maupun minuman jahe merah berbentuk serbuk. Hal ini akan memudahkan peserta untuk nantinya membuat minuman kesehatan secara mandiri, dan kedepannya dapat meningkatkan perekonomian masyarakat.

Peserta pengabdian masyarakat ini, yaitu kader PKK RW 03 sudah banyak yang berusia lanjut sehingga terkendala dalam membuat minuman kesehatan, sehingga diharapkan untuk kegiatanm ini dapat diberdayakan berasal dari segmen masyarakat dari karang taruna atau pemuda yang lebih memiliki semangat dan kemampuan lebih besar dalam mengolah minuman kesehatan.

\section{UCAPAN TERIMA KASIH}

Terimakasih kami ucapkan kepada LPPM UPN "Veteran" Jakarta yang telah memberikan dana dan memberi dukungan atas kegiatan pengabdian masyarakat ini. Terimakasih pula kami ucapkan kepada Bapak Ketua RW 03 Depok Jaya Pancoran Mas Depok beserta 11 RT dibawahnya beserta jajarannya dan Ketua PKK RW 03 beserta jajarannya serta segenap masyarakat di RW 03 atas semua ijin, bantuan, fasilitas dan kerjasamanya sehingga kegiatan ini dapat berjalan dengan lancar.

\section{Daftar Pustaka}

1. Acuan Sediaan Herbal, 2. 2006. Jakarta: Departemen Kesehatan RI, Badan POM, Direktorat Obat Asli Indonesia.

2. Dalimartha, S. 2000. Atlas Tumbuhan Obat Indonesia, 2. Jakarta: Trubus Agriwidya, Jakarta. 
3. Duaja, M., Buhaira, Nelyati, \& E. Kartika. 2018. Pemberdayaan masyarakat Desa Sri Agung untuk meningkatkan ketahanan pangan dengan introduksi padi hitam di pekarangan. Riau Journal of Empowerment 1(1): 37-43. https://doi.org/10.31258/raje.1.1.5

4. Hastuti, S. Setyawati, \& N. Khotimah. 2014. Pemberdayaan Ibu Rumah Tangga di Desa Purwobinangun Kecamatan Pakem Kabupaten Sleman Dalam Penanaman Dan Pemanfaatan Tanaman Obat Keluarga (TOGA). Yogyakarta: Universitas Negeri Yogyakarta.

5. Herbal Indonesia Berkhasiat: Bukti Ilmiah \& Cara Racik. 2008. Trubus Info Kit, 08. Depok: PT Trubus Swadaya.

6. Kementerian Kesehatan RI. 2011a. 100 Top Tanaman Obat Indonesia, Badan Penelitian dan Pengembangan Kesehatan Balai Besar Penelitian dan Pengembangan Tanaman Obat dan Obat Tradisional. Jakarta: Kementerian Kesehatan RI.

7. Kementerian Kesehatan RI. 2011b. Pedoman Pengolaan dan Pemanfaatan Tanaman Obat Keluarga (TOGA). Jakarta: Direktorat Bina Pelayanan Kesehatan Tradisional Alternatif dan Komplementer, DIRJEN Bina Gizi dan Kesehatan Ibu dan Anak.

8. Kementerian Kesehatan RI. 2012. Pedoman Penilaian Pengelolaan dan Pemanfaatan Tanaman Obat Keluarga (TOGA). Jakarta: Kementerian Kesehatan RI.

9. Mun'im, A., \& E. Hanani. 2011. Fitoterapi Dasar. Jakarta: Dian Rakyat.

10. Profil Kesehatan Kota Depok. 2013. https://dinkes.depok.go.id. Diakses pada 19 April 2018.

11. Serial Teknologi Obat Asli Indonesia Gel Rimpang Jahe Merah. 2014. Jakarta: Departemen Kesehatan RI, Badan POM, Direktorat Obat Asli Indonesia.

12. Soverda, N., Z. Alamsyah, E. Indraswari, Y. Alia, \& Neliyati. 2018. PPM Kelurahan Teratai Kecamatan Muara Bulian dalam upaya pemanfaatan lahan pekarangan untuk peningkatan produksi dan kualitas tanaman jahe merah. Riau Journal of Empowerment 1(1): 45-49. https://doi.org/10.31258/raje.1.1.6

13. Suharmiati, \& L. Handayani. 2007. Tanaman Obat \& Ramuan Tradisional Untuk Mengatasi Demam Berdarah Dengue. Jakarta: PT Agro Media Pustaka Jakarta.

14. Suparni, \& Wulandari. 2012. Herbal Nusantara, 1001 Ramuan Tradisional Asli Indonesia. Yogyakarta: Rapha Publishing.

15. Supriatna, M. Febriyanti, Dewanto, \& I. Wijaya. 2012. Fitoterapi Sistem Organ Pandangan Dunia Barat Terhadap Obat Herbal Global. Bandung: UNPAD Press.

16. Sutrisno, B. 1998. Taksonomi Tumbuhan untuk Farmasi. Jakarta: Fakultas Farmasi Universitas Pancasila Jakarta.

17. Syahza, A., D. Bakce, \& B. Asmit. 2018. Increasing the awareness of palm oil plantation replanting through farmers training. Riau Journal of Empowerment 1(1): 1-9. https://doi.org/10.31258/raje.1.1.1

18. Tuloli, T. Sutriyanti, \& A. Mustapa. 2016. Pemberdayaan Ibu Rumah Tangga Desa Suka Makmur Kecamatan Tolangohula Kabupaten Gorontalo Dalam Penanaman Dan Pemanfaatan Tanaman Obat Keluarga (TOGA). Gorontalo: Universitas Negeri Gorontalo.

19. Winarto. 2007. Tanaman Obat Indonesia Untuk Pengobat Herbal. Jakarta: Karyasari Herba Media. 